\title{
Plant-Morphing Strategies and Plant-Inspired Soft Actuators Fabricated by Biomimetic Four-Dimensional Printing: A Review
}

\section{Luquan Ren ${ }^{1}$, Bingqian Li ${ }^{1}$, Kunyang Wang ${ }^{1}$, Xueli Zhou' ${ }^{1}$, Zhengyi Song ${ }^{1}$, Lei Ren ${ }^{2 *}$ and Qingping Liu'*}

${ }^{1}$ Key Laboratory of Bionic Engineering, Ministry of Education, Jilin University, Changchun, China, ${ }^{2}$ School of Mechanical, Aerospace and Civil Engineering, University of Manchester, Manchester, United Kingdom

For prey, seeding, and protection, plants exhibit ingenious adaptive motions that respond autonomously to environmental stimuli by varying cellular organization, anisotropic orientation of cellulose fibers, mechanical instability design, etc. Notably, plants do not leverage muscle and nerves to produce and regulate their motions. In contrast, they harvest energy from the ambient environment and compute through embodied intelligence. These characteristics make them ideal candidates for application in self-morphing devices. Four-dimensional (4D) printing is a bottom-up additive manufacturing method that builds objects with the ability to change shape/properties in a predetermined manner. A versatile motion design catalog is required to predict the morphing processes and final states of the printed parts. This review summarizes the morphing and actuation mechanisms of plants and concludes with the recent development of 4D-printed smart materials inspired by the locomotion and structures of plant systems. We provide analyses of the challenges and our visions of biomimetic 4D printing, hoping to boost its application in soft robotics, smart medical devices, smart parts in aerospace, etc.

Keywords: soft actuators, biomimetic 4D printing, bioinspired, plant-morphing strategies, plant-inspired soft actuators

\section{INTRODUCTION}

Nature endows many organic systems with shape-morphing features, particularly the plant kingdom (Poppinga et al., 2020). Unlike animals, where macroscopic movement is provided by chemical reaction in the molecule level, the locomotion of plants is delivered by microscopic swelling of the cells (Forterre, 2013). After evolution for billions of years, plant organs are gifted with the ability to respond to environmental changes by regulating constituents and structures, forming the "morphological computation" in their growth and reach a final configuration before maturation (Pfeifer and Gomez, 2009; Guo et al., 2015). In reaction to variability within their surroundings, they continuously adjust their morphology and physiology. The dynamic interactions between their morphology and the environment contribute to the adaptability of the plant system, which also generates the principle of "morphological computation" (Zambrano et al., 2014). A representative example of morphological computation is the "passive movements." For example, pine cones open their scales in dry conditions and close them when hydrated. The organization of plant cell walls accounts for motion, where a soft matrix and stiff embedded 


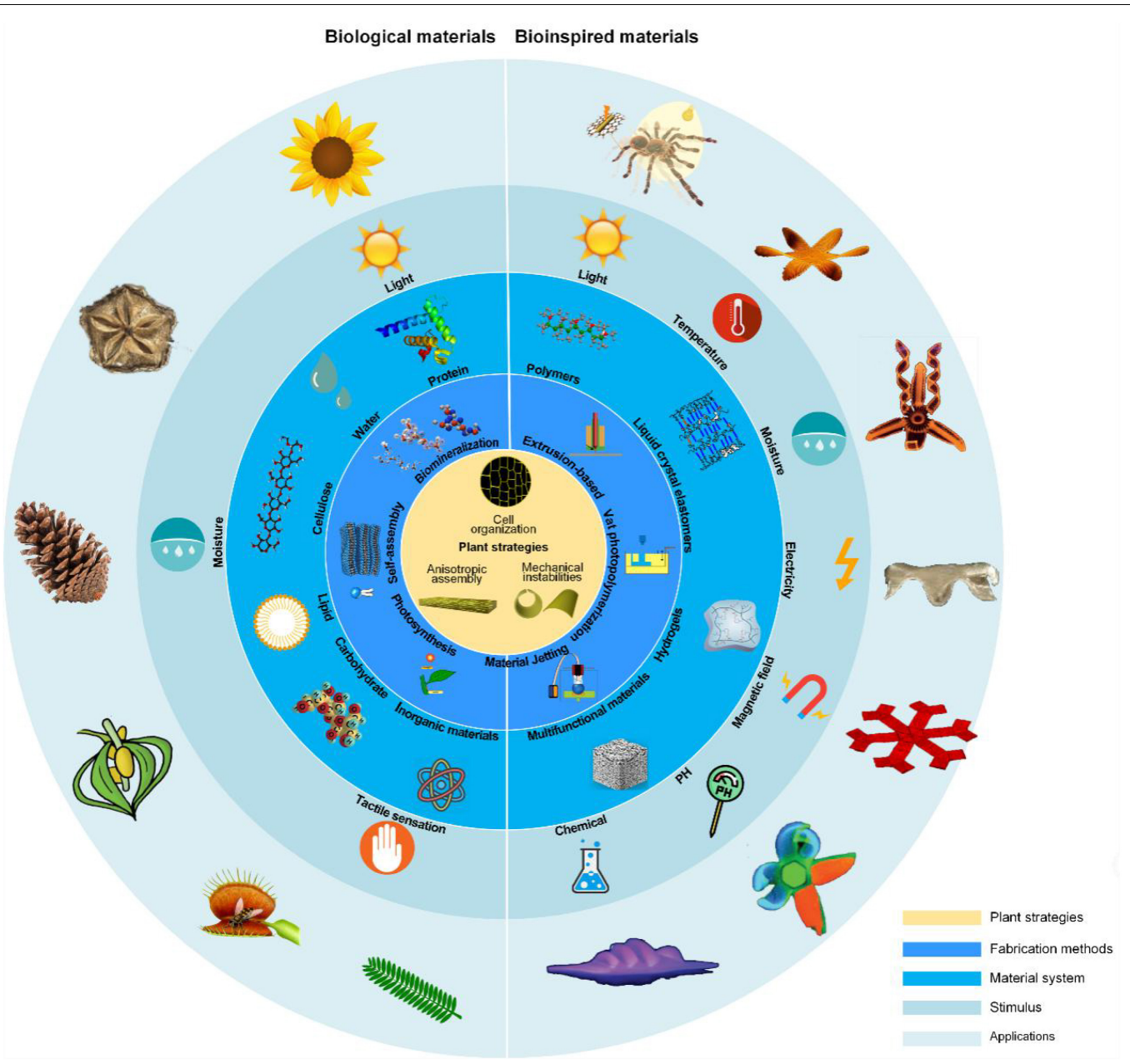

GRAPHICAL ABSTRACT | The plant-morphing strategies, manufacturing methods, materials, stimuli and applications of biological and bioinspired material.

cellulose fibrils drive the movement of the plant organ (Dawson et al., 1997). These systems sense and respond to surrounding changes without additional energy inputs, making them ideal for soft actuations. Similar to the environment of plants, the operating environment of artificial soft actuators is also dynamic (Pfeifer et al., 2012). Structural designs that can self-adapt in both controlled and uncontrolled environments are urgently required.

Biomimetics is a multidisciplinary discipline that examines bio-phenomenology for gaining inspiration in developing artificial systems (Vincent et al., 2006). It is divided into "bottom-up" and "top-down" process (Hashemi Farzaneh et al., 2016), and both of them requires the steps of abstracting, transferring, and applying. The abstracting demands acknowledging the associations of the structural-functional properties of plants. The transferring and applying are not the direct "copy and paste" process but an innovative process, similar to heredity and variation in species evolution process (Gregory, 2009). The bioinspired soft actuators usually consist of delicate and sophisticated heterogeneous structures and are constructed from materials with mechanical properties analogous to living materials (Miriyev et al., 2017). Thus, designing and manufacturing bioinspired soft actuators are extremely challenging for traditional technologies, which desires an innovative way rather than artificially assembling elementary blocks like rigid-body actuators (Cho et al., 2009).

Four-dimensional (4D) printing, stemming from the rapid development of 3D printing, smart materials, and systematic programming routes, is an effective way of transferring biological counterparts into artificial structures (Momeni et al., 2017). By incorporating 3D printing technology with smart materials, the concept of $4 \mathrm{D}$ printing is proposed to realize components that can regulate their morphologies responding to external stimuli (De Marco et al., 2018). The selection of deformation materials is based on their response to environmental excitation (Shafranek et al., 2019). The establishment of mathematical models and motion design catalogs is required to predict the fourth dimension (Boley et al., 2019; Kanu et al., 2019). $4 \mathrm{D}$ printing is a new manufacturing paradigm that produces tunable intricate 3D structures induced from the 2D counterpart (Yang et al., 2020). In addition, it is a disruptive strategy to construct dynamic structures that can alter their structure, function in a scheduled way (Montero de Espinosa et al., 2017), 


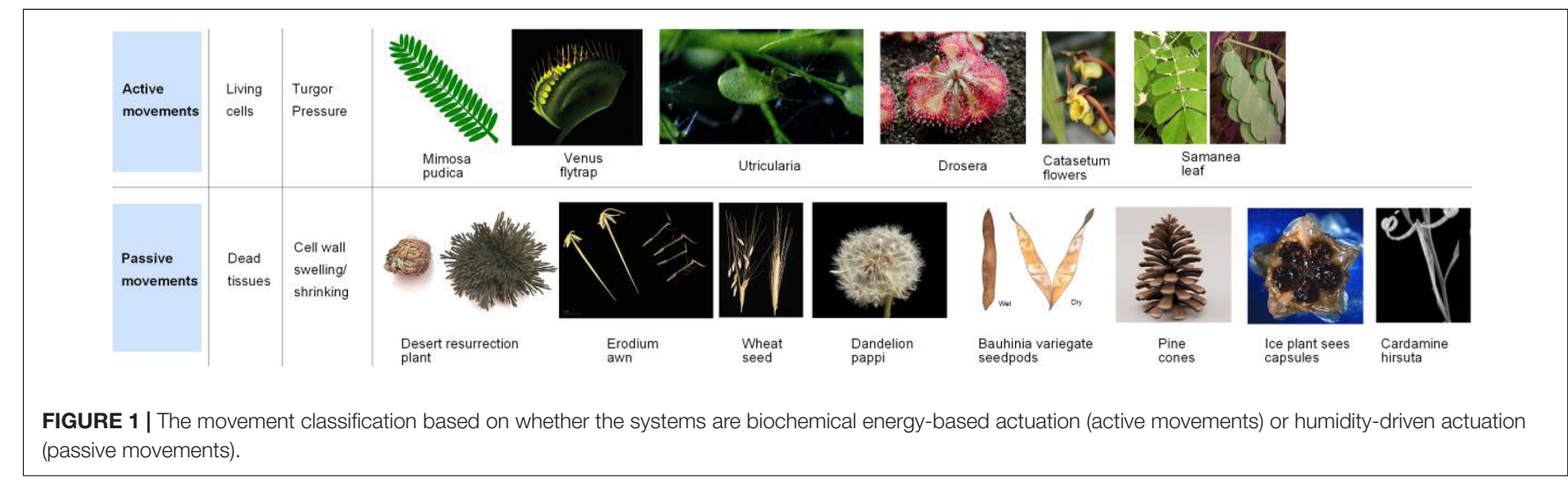

which has a variety of applications in MEMS (Sundaram et al., 2017), soft robots (Gul et al., 2018), sensors (Tseng et al., 2018), deployable mechanism (Yang et al., 2019), active arts and costume (Sun et al., 2020), and controlled release medicine (Durga Prasad Reddy and Sharma, 2020).

Biomimetic 4D printing can translate biologically extracted motifs into synthetically dynamic materials via the bottomup accumulation of materials (Sydney Gladman et al., 2016). It needs to undergo the abstracting, transferring process first, and then applying the transferred motifs via appropriate $3 \mathrm{D}$ printing technologies.

Now, most of the reviews about $4 \mathrm{D}$ printing mainly focus on smart materials, printing technologies, and various applications (Mitchell et al., 2018; Kuang et al., 2019a; Zhang et al., 2019). In this review, we concentrate on soft actuation structural designs in plant systems and biomimetic soft actuators with the assistance of $4 \mathrm{D}$ printing. We first introduce the movements in the plant system and then conclude with three strategies from various movements: cellular organization, orientation of the cellulose fibers, and mechanical instabilities. Then, we briefly introduce the $4 \mathrm{D}$ printing technologies. Next, the bioinspired programming approaches are classified based on whether it is mimicking locomotion or designs of the plant system. These programming methods based on designs from the plant system can be further subdivided into structure-driven $4 \mathrm{D}$ printing, parameter-driven $4 \mathrm{D}$ printing, and stimulus-driven $4 \mathrm{D}$ printing in the light of which is the determinative factor of shapemorphing process. Finally, we propose the challenges and outlook for the biomimetic $4 \mathrm{D}$ printing of soft actuators to give some sparks for future researches.

\section{THE MOVEMENTS AND STRUCTURAL STRATEGIES IN THE PLANT SYSTEM}

Although plants do not have muscles, they can produce many different movements in a time frame ranging from a few days to a few milliseconds (Forterre, 2013). Their natural formations from micro- to macroscale endow them with capabilities to adapt to the environment without the processing of the nerve system. Plants are capable of responding to a variety of signals and the movements observed are characteristic of the structures, not a consequence of metabolic processes (Studart and Erb, 2014). Therefore, these principles widely existing in the plant world are more easily extracted and applied to soft actuators.

\section{The Movement Behaviors in the Plant System}

The movement of plants is usually categorized into two types: tropistic and nastic movements (Guo et al., 2015). Tropistic movement is the directional actuation in response to stimuli such as gravity, light, and mechanical touches. For example, the growth of tendrils depends on the location and manner in which they contact the supporting object (Scorza and Dornelas, 2011). On the other hand, nastic movements are direction independent in response to stimuli. As a case in point, the closing of the Dionaea trap does not rely on the location and orientation of the sensitive hairs being touched (Braam, 2005).

Some studies also discriminated between active and passive systems in plant locomotion based on whether they are biochemical energy-based actuation or humidity-driven actuation (Egan et al., 2015) (Figure 1). The active systems rely on moving ions to alter membrane permeability (Yang and Hinner, 2015), resulting in reversible turgor changes and irreversible growth processes under the stimulation of various types of stimuli (touch, temperature, or light). Plants are allowed to generate motions such as blooming and wilting of flowers, closing of Venus flytraps, and folding of mimosa leaves (Jung et al., 2014). The resulting actuation can be high speed as in Mimosa pudica (defense, $<1$ s) and Venus flytrap (nutrition, $\approx 100 \mathrm{~ms}$ ) (Forterre et al., 2016). Notably, the number and properties of cells as well as the exchanging capacity of water limit the performance of the movements (e.g., the amplitude, speed, and frequency). Passive motion refers to the change in configuration of dead tissue in response to environmental changes (Quan et al., 2020). They are already dead tissues that are subject to scheduled changes. The wall of plant cells is a composite that constitutes cellulose microfibrils, polysaccharides, hemicellulose, soluble proteins, etc. (Fagerstedt and Karkonen, 2015). The soft matrix inside the cell wall expands when combined with water molecules. Specifically, the hydrophilic moiety allows water molecules to be stored via hydrogen bonding. Many organ movements in plants are triggered by 
changes in the water content of cell walls (pine cones, Selaginella lepidophylla, Erodium gruinum, seed pods, ice plant seeds, dandelion) (Montero de Espinosa et al., 2017). For example, the ancient resurrection plant, $S$. lepidophylla, shows a dramatic curl and uncurl as the plant hydrates. When dehydrated, the stems of S. lepidophylla curl, eventually forming a rough sphere (Selaginella et al., 2015). The hygroscopic reactions also induce the opening and closing of pine cones (Reyssat and Mahadevan, 2009), release of seed pods (Armon et al., 2011), and self-burial of the wheat awns and Erodium seeds (Evangelista et al., 2011).

Compared with the aforementioned osmotic pressure actuation, hygroscopicity is relatively slow; however, the merit lies in the fact that it does not require any biochemical energy. However, it is not always the case because rapid movements could be achieved by dehydration of dried tissues with the delicate structure designs (mechanical instabilities) (Guo et al., 2015). The passive actuation systems that are not dependent on living cells offer us an excellent source of inspiration.

\section{The Structural Strategies for Movements in the Plant System}

The time scale of water diffusion in each tissue determines the speed of motile plant structures. In general, larger plant organs require longer time for water transport, of which some plants have evolved elastic instability to overcome the inherent defect (Skotheim, 2005). The sudden release of energy greatly increases the speed of movement, which is reversible as long as the tissue is not damaged. Elastic instability has been found in many examples of explosive diaspore dispersal. Venus flytrap is one of the representative examples, where the geometric change of its lobes from concave to convex substantially improves the speed of snapping (Forterre et al., 2005).

To enable nonuniform slow/fast sophisticated movements with uniform hygroscopic actuations, plants have evolved various delicate strategies: (1) cellular organization, (2) orientation of the cellulose fibers, and (3) mechanical instabilities (Figure 2). It should be noted that the above briefly summarized plant movements and strategies are only the tip of the iceberg. There are many other reviews providing a broader overview about the plant actuation mechanisms and applications (Poppinga et al., 2016).

\section{Cellular Organization}

In the active and passive actuation systems, cellular organization (distribution, density, morphology, etc.) is a frequently used measure to confer various movements to homogeneous materials, for example, the locomotion of pulvinus stems from the volume change and pressure difference between subepidermal and supraepidermal motor cells (Volkov et al., 2010a). Besides, some passive systems, such as S. lepidophylla mentioned above, curl their stems to form spheres (Selaginella et al., 2015). They are also caused by the cell density variation within the lower and upper regions of the dry tissue. Another passive actuation example is ice plant seed capsule. To enable seed dispersal, its keel cells have evolved ellipsoid-hexagonal shape, translating a isotropic swelling into a unidirectional deformation and, thus, unfolding of the capsule (Guiducci et al., 2016).

\section{Anisotropic Reinforcement of the Cellulose Fibers}

Plant cell wall consists of stiff and orientationally distributed cellulose fibers. The swelling of plant cell walls occurs in a hygroscopic soft matrix, where the direction of moisture absorption and expansion is vertical to the direction of cellulose microfibrils. The underlying principle is the constant length along the fiber alignment and expansion in the perpendicular direction under the stimulation of moistures. Hygroscopic bending and torsional movements in many organs, such as pine cones, wheat awn, and chiral seed pods, have a close association with the variations in fiber orientations (Elbaum and Abraham, 2014). In pine cones, the hinge at the base of the scales consists of two layers of hygroscopic tissue embedded with cellulose fibers (Reyssat and Mahadevan, 2009). These aligned fibers restrict any longitudinal shape changes in the embedded layer. Therefore, reciprocal bending of the pine cone scales can be achieved with the variation of environmental humidity. Besides, the architected orientation of the cellulose fibers enables self-burial of the seed. Erodium cicutarium consists of inclined spiral fibers whose seeds show self-buried motion due to the rotation of the awn under changes in humidity (Jung et al., 2014). Specifically, the orientation of the material fibers causes awns to curl in low air humidity and to straighten in high air humidity, thus leading to the burial of the seed. The soft tissues of trees adopt a similar strategy that involves reorienting cellulose fibers in the cell wall to generate stress and thus change the direction of growth (Du and Yamamoto, 2007).

\section{Mechanical Instabilities}

The speed of water diffusion limits the response times of both osmotic pressurization and hygroscopic swelling/shrinking merely by ion transportation and the hydrophilic process. In order to move quickly, mobile organs either need to be miniaturized, as in the case of the hydraulically driven Mimosa pulvinus (Volkov et al., 2010b), or rely on mechanical instability and designed failure modes (Dumais and Forterre, 2012). The plant employs structural strategies (bistability, fracture, and water cavitation) to overcome the physical limitation (Figure 3). Indeed, the velocity, accuracy, and efficiency of the fast movements of plants are as essential as the muscledriven movements in animals. First, the bistable mechanism not only produces fast motion but also reversible motion, which is attractive for artificial designs. The bistable system can be maintained at stable states without the need for consistent pressure supply, achieving rapid and reversible deformation with minimal pressure changes.

One of the most intensively studied plant movement using bistability is the Venus flytrap (Hedrich and Neher, 2018). The trap consists of two connected lobes, and the inner surface of each lobe has many triggering hairs. The closing of Venus flytraps occurs when small hairs are triggered by the movement of insects. Two or more trigger events can cause the trap to close, and thus, avoid closing when there is no prey present. The trap usually shuts in tenths of a second. A carnivorous plant in eastern Australia, Drosera glanduligera, also uses snapping tentacles to catapult prey into sticky traps (Poppinga et al., 2012). First, tentacles at the trap periphery quickly flung the prey onto the 


\section{Cell organization}
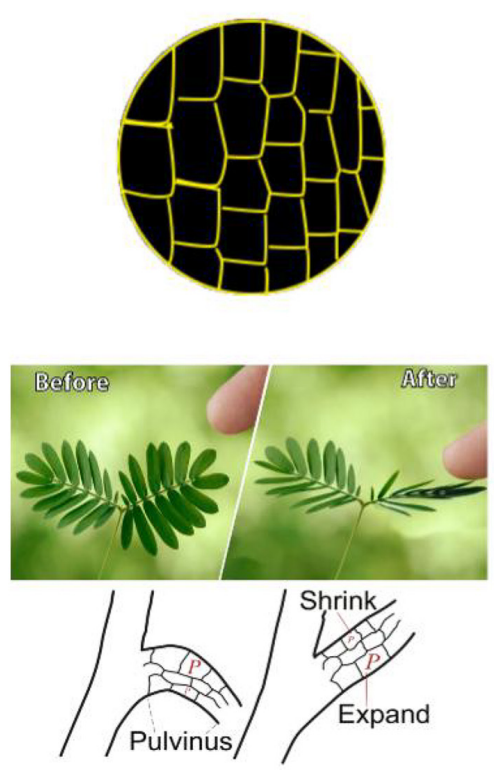

\section{Anisotropic orientation}

\section{Mechanical instabilities}
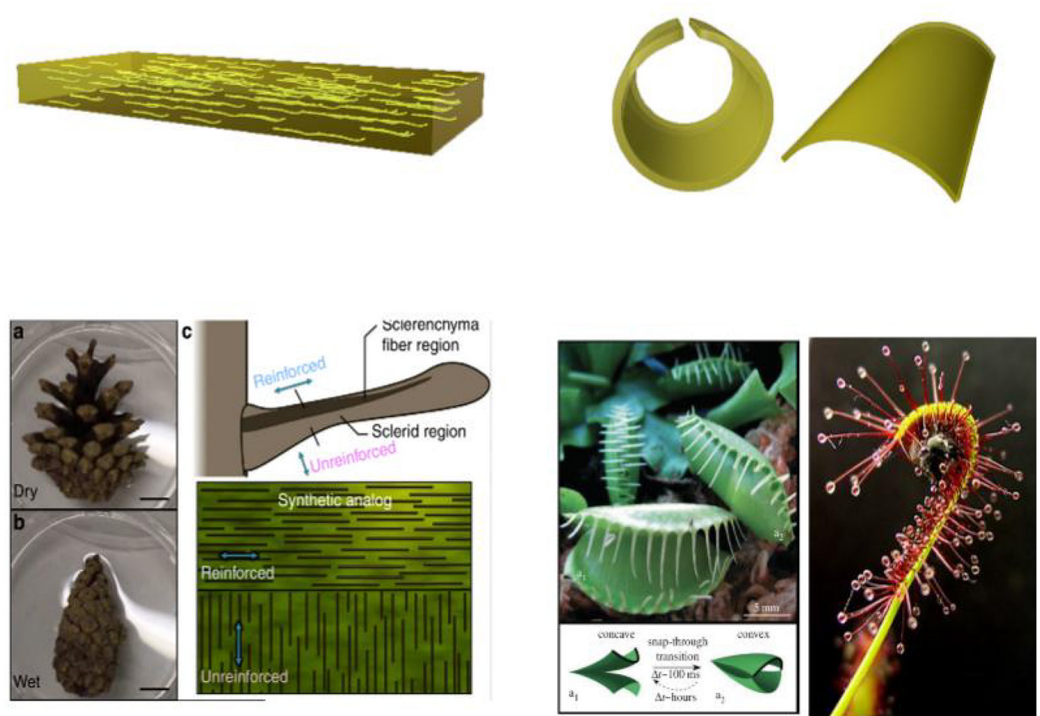

FIGURE 2 | The three structural strategies of actuation in the plant system (cell organization, anisotropic reinforcement, and mechanic instabilities).

\section{Fast movements/shooting mechanisms}

\section{Bistable snap-through mechanism}

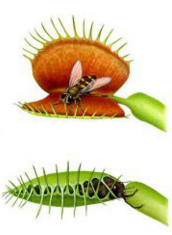

Venus

flytrap

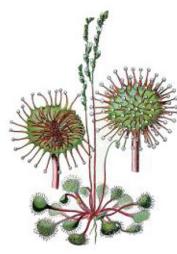

Drosera glanduligera
Fracture release mechanism

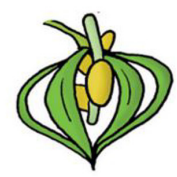

Impatiens capensis

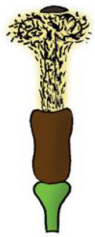

Genus sphagnum

\section{Cavitation release mechanism}

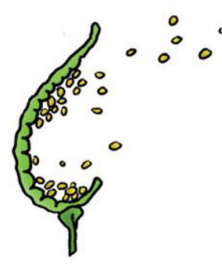

Common ferns

FIGURE 3 | Further classification of mechanic instabilities into bistable snap-through mechanism, fracture release mechanism, and cavitation release mechanism.

adhesive tentacles of the leaf blade in about $0.1 \mathrm{~s}$ when stimulated. Then, the glue tentacles move the prey to the concave center of the leaf to digest.

The other elegant and well-studied cases are based on fracture release whose deformations are usually nonreversible. For instance, Impatiens glandulifera relies on fracture mechanics to spread its spores. Although the fracturing seems like a result of mechanical instability, it still differs from buckling since it is a one-shot process (Deegan, 2012). It consists of five elongated and curved segments or valves, and each has 5-10 seeds held inside. In the initial state, the valves are straightened by interconnection of individual valves. When one of the valves is deformed because of drying or changes in external conditions, the chain reaction will begin. The geometry of the remaining valve undergoes a cascade of changes, the seam breaks, and the elastic energy is released instantaneously. The reaction resulted in explosive dehiscence, with the seeds being spread $2 \mathrm{~m}$ away from the parent plant and reaching a peak emission velocity of $4.1 \mathrm{~m} / \mathrm{s}$. Another fracture example is the spores of Sphagnum. It is developed within spherical capsules comprised of two portions containing the upper spore-filled and the bottom air-filled chamber (Sakes et al., 2016). In the water loss state, the matured drying capsules 
contract radially and migrate their shape from spherical to cylindrical. Then, the decreasing capsule volume leads to an increase in air pressure until a critical pressure is reached. The explosively released spores are capable of achieving a peak acceleration of $36,697 \mathrm{~g}$ and a peak launch velocity of $30 \mathrm{~m} / \mathrm{s}$ and propelling the spores to $0.20 \mathrm{~m}$ above the moss.

Cavitation-based spore discharge is often observed in the family ferns (Poppinga et al., 2015). A stalk and a circular ridge of 12 or 13 cells comprise the spore structure of common ferns. Evaporation of water from the cytoplasm of the cell causes the interior of the lateral wall to collapse, allowing the annulus to open to expose the spores and leading to a sudden release of the stored elastic energy $(\sim 0.01 \mathrm{~ms})$. This peak launch acceleration, the peak launch velocity, and the launch distance are approximately $100,000 \mathrm{~g}, 10 \mathrm{~m} / \mathrm{s}$, and $0.057 \mathrm{~m}$, respectively.

\section{D PRINTING-RELATED TECHNOLOGIES}

The concept of $4 \mathrm{D}$ printing combines ongoing 3D printing technology with smart materials to enable printed components that transform their morphology in response to environmental stimuli. The two most vital components in $4 \mathrm{D}$ printing are materials and 3D printing technology, and the selection of materials determines the $3 \mathrm{D}$ printing technology utilized. The states of the raw materials, physical and chemical properties, curing requirements, special processing needs, etc. all determine the specific $3 \mathrm{D}$ printing process that is applicable. There are broad options for $3 \mathrm{D}$ printable materials, including shape memory polymers, hydrogels, liquid crystal elastomers, metals and alloys, ceramics, and composites (McCracken et al., 2020). Among these methods, direct ink writing (DIW), fused depositing modeling (FDM), stereolithography (SLA), digital light processing (DLP), material jetting, and selective laser sintering (SLS) are most commonly employed in 4D printing (Deshmukh et al., 2019) (Table 1).
Fused depositing modeling and DIW are both extrusionbased and form a 3D object in a line by line and layer by layer way. The differences stem from their raw materials that FDM melts a solid filament in a heating nozzle and then solidifies materials by cooling. DIW, on the other hand, deposits a viscous liquid ink that can be cured simultaneously or subsequently by UV light, heat, etc. Extrusion-based methods have the advantage of printing a wide range of materials, including various engineered thermoplastic polymers, hydrogels, colloidal materials, and compounds, which can be in solid, liquid, or paste form. The printing resolution of FDM and DIW is mainly limited by the nozzle diameter $(100-400 \mu \mathrm{m})$. The SLA and DLP are both vat photopolymerization-based methods. A laser beam for photocuring is called SLA; a projector used for photocuring is called DLP. The curing methods of DLP are not confined to photocuring. Vitrification, evaporation, and polymerization can all be applied into the solidification of the materials. The resolution of SLA and DLP is mainly determined by the curing method, and both laser and projector can reach the resolution of 1-50 $\mu \mathrm{m}$. In the recent researches of $4 \mathrm{D}$ printing, the use of switchable vats and tunable light contributes to the advances in multimaterial DLP. Another popular method is material jetting, which utilizes multiple nozzles for spraying different resins to form a layer, and the process is accompanied by subsequent UV curing or lasing. It allows the manufacture of composite materials with various properties at a relatively high resolution with an in-plane resolution of $16 \mu \mathrm{m}$ for single-material printing. The last method, selective laser sintering (SLS), is a powder bed fusion-based method, which uses a laser (electron beam) to melt thermoplastic powders together. Its resolution can be as fine as $100 \mu \mathrm{m}$, depending on the powder granularity and heat source.

In the research of $4 \mathrm{D}$ printing of soft actuators, FDM and SLA are the most extensively used printing techniques followed by material jetting and DIW. DLP is also a recently emerged technique with a huge potential for printing $4 \mathrm{D}$ active devices. In the next section, we will review the $4 \mathrm{D}$ printing of the soft actuators inspired by the plant system using the abovementioned printing technologies.

TABLE 1 | The introduction of 3D printing technologies applied in 4D printing -raw materials, resolutions, and curing methods.

\begin{tabular}{|c|c|c|c|c|c|}
\hline $\begin{array}{l}\text { Dtreck ink writing } \\
\text { (DIW) }\end{array}$ & $\begin{array}{l}\text { Fused deposition } \\
\text { modeling (FDM) }\end{array}$ & $\begin{array}{l}\text { Stereolithography } \\
\text { (SLA) }\end{array}$ & $\begin{array}{l}\text { Digital light } \\
\text { processing (DLP) }\end{array}$ & Material jetting & $\begin{array}{l}\text { Selective lase } \\
\text { sintering (SLS }\end{array}$ \\
\hline \multicolumn{6}{|l|}{ Raw materials } \\
\hline $\begin{array}{l}\text { Ink, thermoplastic } \\
\text { grain }\end{array}$ & $\begin{array}{l}\text { Thermoplastic } \\
\text { filament }\end{array}$ & $\begin{array}{l}\text { Low viscosity ink } \\
(\mathrm{V}<5 \mathrm{~Pa}-\mathrm{s})\end{array}$ & Low viscosity ink & $\begin{array}{l}\text { Low viscosity ink } \\
(\mathrm{V}<0.2 \mathrm{G} \mathrm{Pa-s})\end{array}$ & $\begin{array}{l}\text { Thermoplastic } \\
\text { powder }\end{array}$ \\
\hline \multicolumn{6}{|c|}{ Approximate resolutions } \\
\hline $1-100 \mu \mathrm{m}$ & $100 \mu \mathrm{m}$ & $1-50 \mu \mathrm{m}$ & $1-50 \mu \mathrm{m}$ & $50 \mu \mathrm{m}$ & $100 \mu \mathrm{m}$ \\
\hline \multicolumn{6}{|l|}{ Curing methods } \\
\hline $\begin{array}{l}\text { UV light, } \\
\text { crosslinking, } \\
\text { heating }\end{array}$ & Cooling & Laser & $\begin{array}{l}\text { Verification, } \\
\text { evaporation, } \\
\text { polymerization, UV light }\end{array}$ & Laser, UV light & Laser \\
\hline
\end{tabular}




\section{D PRINTING OF SOFT ACTUATORS INSPIRED BY THE PLANT ACTUATION SYSTEM}

$4 \mathrm{D}$ printing incorporates additive manufacturing processes with dynamic materials, providing an effective tool for nextgeneration soft actuators. However, these methods lack theoretical models, and the relationship between material distribution, structure, and function needs to be thoroughly studied. There is a growing recognition that the actuation mechanisms of plants can provide inspiration for the development of bioinspired soft actuators. Plants hold a multitude of movement mechanisms, which are increasingly recognized as sources of inspiration for the development of bioinspired actuators. The motile plant structures without localized hinges introduced in the Section "The Movements and Structural Strategies in the Plant System" are ideal candidates as concept generator. In general, soft actuators mimicking plants are subdivided into plant locomotion-inspired actuation and plant design-inspired actuation, both of which have their advantages and disadvantages. Plant locomotion-inspired soft actuators are often only morphologically similar to plants, and there is still a large gap between the comprehensive performance of artificial soft actuators and plant organs. It outperforms plant design-inspired actuators in terms of design freedom when it comes to achieving specific functions. Plant design-inspired soft actuators derive strategies from plant organs. Although they might have more restrictions when selecting material structures, their deforming mechanisms and comprehensive performances resemble biological counterparts in a superior way.

\section{D Printing of Soft Actuators by Mimicking the Locomotion of the Plant System}

In the existing literature, although some actuators might employ distinct actuation mechanisms from those used in nature, they achieve motions and behaviors quite similar to those of plant organs (Menges et al., 2017; Kim et al., 2018; Kuang et al., 2019b; Alapan et al., 2020). For the soft actuators mimicking the locomotion of plants, the strategies they adopted are based on the characteristics of the material itself (or adjusting the composition of the material) and accompanied by some simple geometric designs. In Figure 4A, Ge et al. (2016) present the sequential recovery of a multimaterial flower by controlling the constituents and compositions of the shape memory polymers in outer and inner petals. Similarly, inspired by the heliotropism of sunflowers (Figure 4B), Lui et al. (2019) printed a photoresponsive shape memory sunflower by combining polymers polyurethane (active materials) and photoresponsive carbon black, resembling an actual sunflower going from bud to bloom. In addition to light and heat actuation, Kim et al. (2018) proposed magnetically responsive soft materials that allow for fast transition between complex 3D shapes based on an elastomer composite containing ferromagnetic microparticles (Figure 4C). The magnetic field applied to the dispensing nozzle during printing reorients the particles along the applied magnetic field. The capability to create complex shape changes of the magnetically responsive soft materials can achieve diverse functions although these structures are not to imitate the movement of plants in this research. Besides, pine cone, flytrap, and M. pudica are also popular biological concept generators. Correa et al. (2020) employed a bilayer region consisting of a directional TPU-bound layer and a directional moisture-absorbing wood polymer layer to program the multiphase motions (e.g., bending deformation of pine cone scales during desiccation) (Figure 4D). Jiang et al. (2019) printed bistable structures with geometries near bifurcation points, and this point is associated with the transfer between bistable and monostable states. As long as the appropriate stimulus is applied, the material will undergo bifurcation, thus triggering large amplitude and fast actuation. They show a similar Venus flytrapinspired example using two more complex actuation units with more complex control logic (Figure 4E) (Jiang et al., 2019). Wang G. et al. (2018) developed an artificial M. pudica actuator via the fused deposition modeling 3D printer by combining the conductive polylactide (PLA) on copy paper. When the leaf is triggered, it can achieve a sequence of actuation similar to that of a M. pudica (Figure 4F) (Wang G. et al., 2018).

\section{D Printing of Soft Actuators by Mimicking the Designs of the Plant System}

Understanding the respective geometry-structure-function relationships of organisms and applying underlying principles to applications would provide a versatile toolbox for generating structures with dynamic responses. We will introduce three programming methods in the subsection, namely using structure design, parameter setting, and imposed stimulus as main motifs to program the shape-morphing behaviors of soft actuators.

\section{The Soft Actuators Mimicked via Structure-Driven 4D Printing}

Like cellular organization in nature, soft actuators can achieve various deformations by the material distributions. Wang et al. (2019) designed a line-shaped composite structure enabling a single printed line with eight bending directions by arranging the active line segment, which is composed of actuator [thermoplastic (PLA)] and constraint regions that are different in shrinkage rates (Figure 5A). By combining multiple segments with varied bending directions, the soft actuators with more complex geometries and complicated functions (grippers) could be fabricated. Besides, the materials can be distributed in three dimensions. Liu et al. (2019) reported the fabrication of 3Dprinted segmented gel tubes consisting of strategic placement of an active swelling gel and a passive nonresponsive gel (Figure 5B). In many cases, the distribution of materials is not clearly bounded, and the transitions between materials are in gradient. By printing graded water-responsive elastomeric materials on heat-shrinkable shape memory polymers, Song et al. (2020) demonstrated a bistimulated self-deforming structure that can produce different shape changes with humidity and temperature to mimic the nonuniform distribution of active ingredients in botany (Figure 5C). 


\section{A}

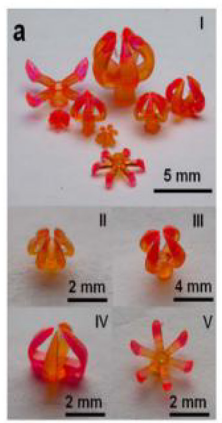

C

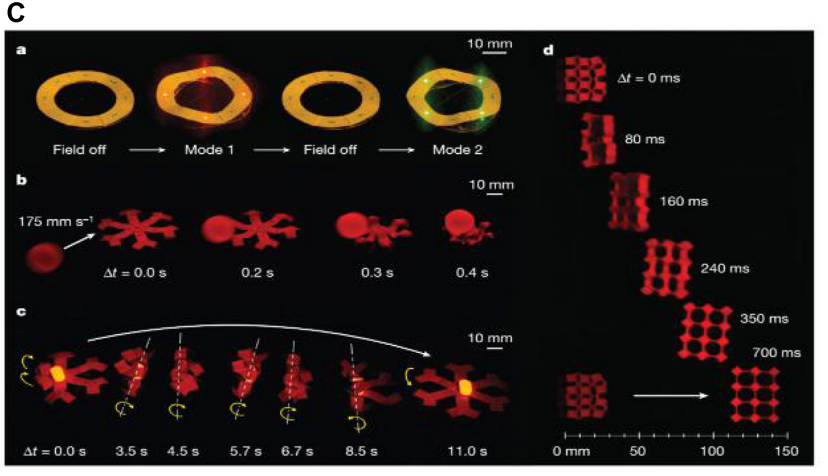

$\mathbf{E}$
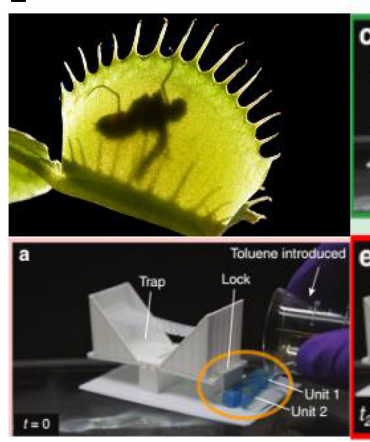

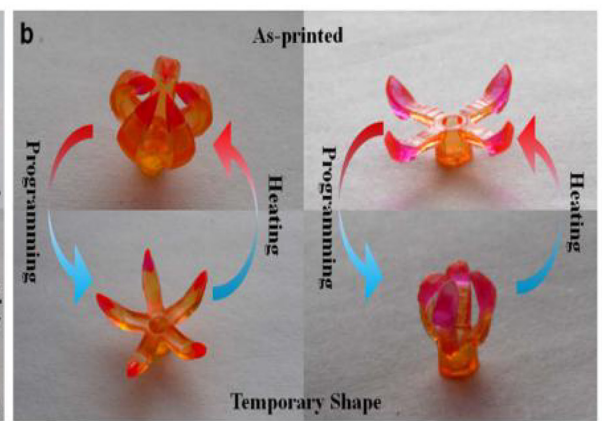

Temporary Shape

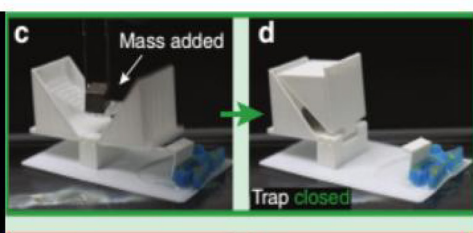

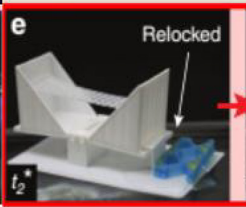

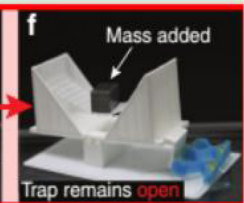

B

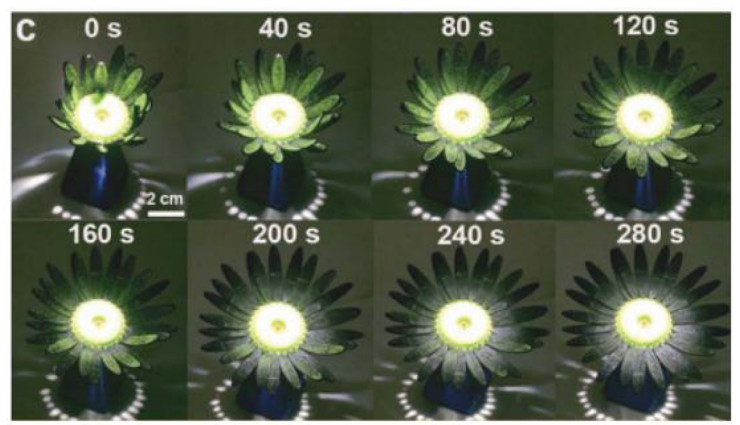

D
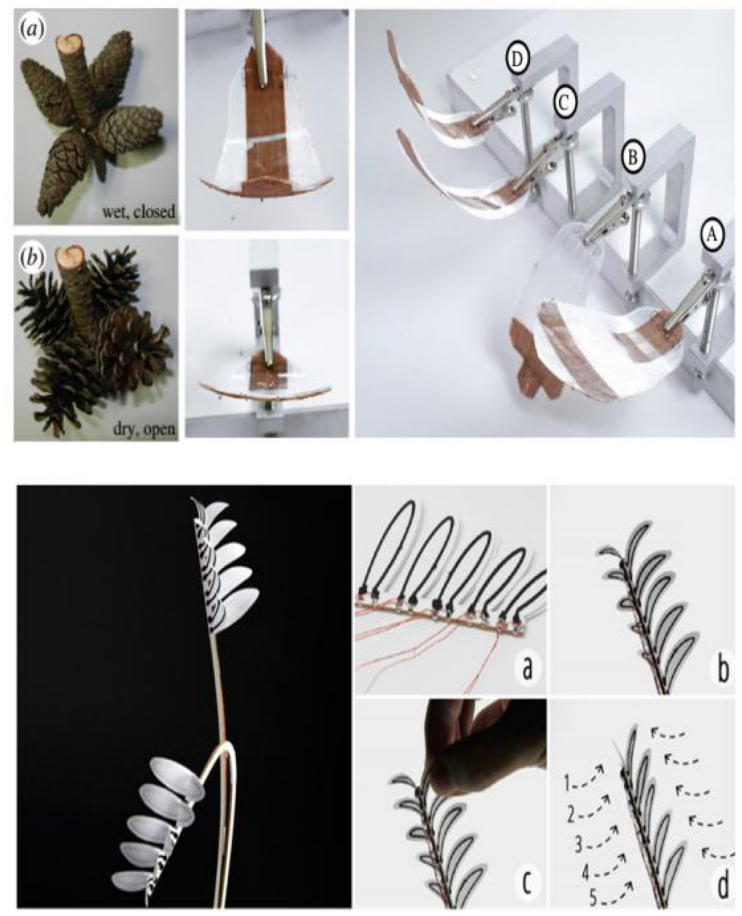

FIGURE 4 | The soft actuators by mimicking the locomotion of plants in nature. (A) Sequential recovery of a multimaterial shape memory actuator mimicking the opening and closing of flowers when triggered by heat. (B) Blooming of the photoresponsive shape memory composites mimicking the opening of flowers when triggered by light. (C) Movements of magnetic responsive soft actuators using programmed magnetic field. (D) Bending of the hygroscopic wood polymer composites mimicking the curvature deformation of pine cones. (E) Fast closing of two bistable units with embodied logic mimicking the trapping process of the Venus flytrap. (F) Sequential actuation of shape memory composites via current-driven Joule heating mimicking the sensing and actuation behaviors of mimosa leaves.

Drawing the principles from the orientation of the cellulose fibers, soft actuators with anisotropic locomotion have been designed and fabricated in the recent research. One of the most representative examples is the hydrogel composite architectures by Lewis and her group (Figure 5D) (Sydney Gladman et al., 2016). They encode local, anisotropic swelling behavior into hydrogel composites via aligned cellulose fibers along the prescribed printing path. Using the theoretical framework of the inverse problem and a plant-inspired architecture, complex 3D morphologies are created when immersed in water. Instead of using nanofibers, Wang W. et al. (2018) chose to program anisotropic shape-morphing behaviors by the design of the print pattern (Figure 5E). Due to the internal strains between bilayers generated in the $3 \mathrm{D}$ printing process, the composite sheets with different print patterns transform to diverse shapes. Thus, they developed a robotic tendril imitating the motions of plant tendrils, which is tailored from a polymer-paper bilayer composite sheet. Besides, some active materials can change from isotropic to anisotropic when exposed to certain processing conditions. Kotikian et al. (2018) reported the fabrication of liquid crystal elastomer actuators with aligned nematic order enabled by the shear force generated in the printing process (Figure 5F). The soft actuators possess complex shapemorphing capabilities by designing the print path, including both $2 \mathrm{D}$ to $3 \mathrm{D}$ and $3 \mathrm{D}$ to $3 \mathrm{D}^{\prime}$ transformations as defined in the research. 


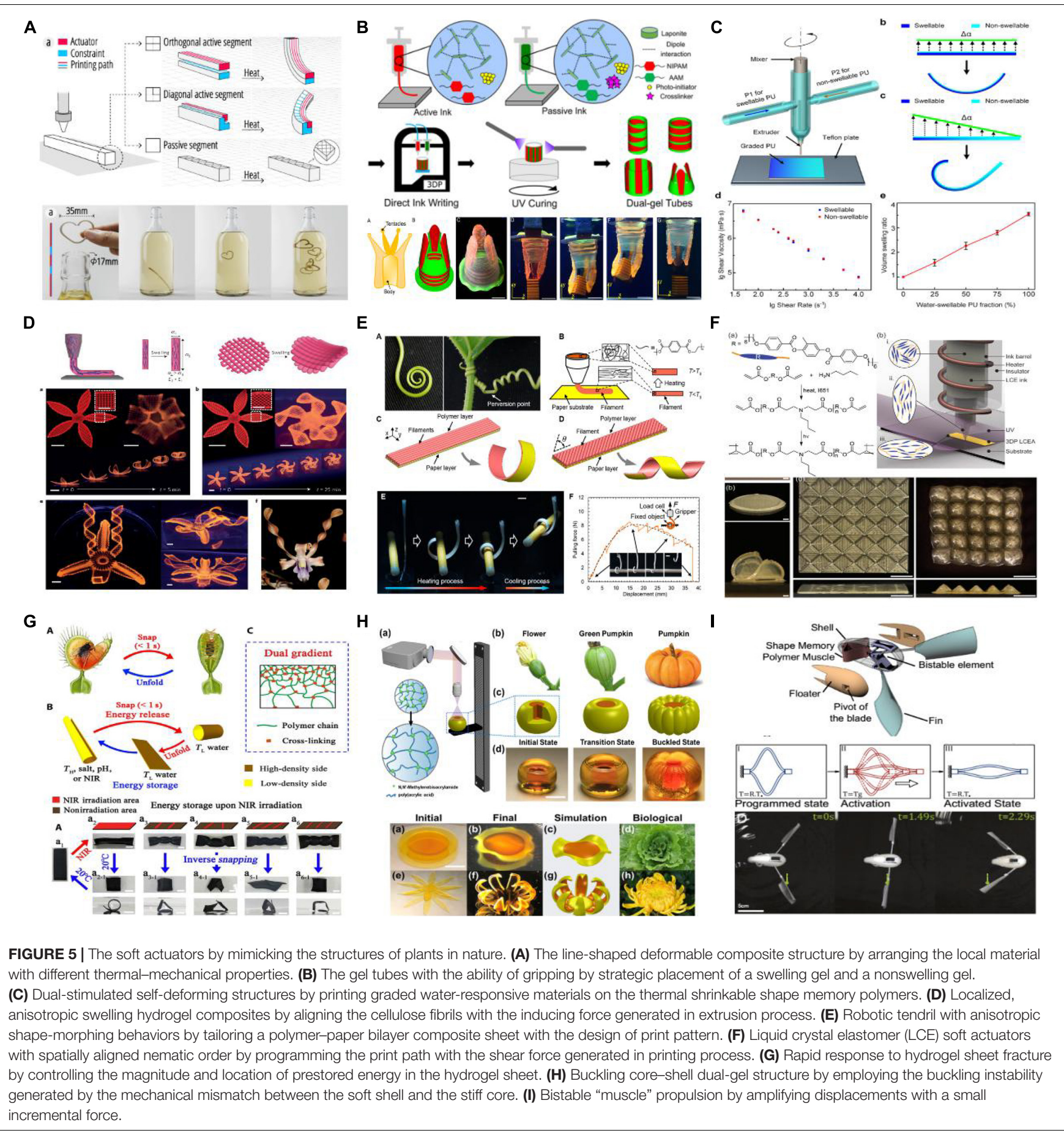

To fabricate soft actuators with fast response, the above two strategies are insufficient to be used as design principles. Mechanical instability, widely existing in the plant and animal world, is then applied to change this situation and enhance the actuation performance. Fan et al. (2019) reported a natureinspired responsive hydrogel sheet with the capability of yielding ultrafast snapping-through deformation (Figure 5G). The snapping of the hydrogel sheet is programmed by controlling the magnitude and location of prestored energy within the hydrogel. Mimicking the circumferential buckling in pumpkins, Yin et al. (2008) reproduced the core-shell double gel structure with bending instability generated by mechanical mismatch between the rigid core-shell and the compliant shell (Figure 5H). It utilizes digital light processing-based technology to design a bending hydrogel, and its buckling behaviors are governed by the radius ratio, swelling ratios, and stiffness mismatch between the core and shell. This design can be widely used for applications like artificial muscle, soft robotics, etc. Chen et al. (2018) created 
responsive bistable "muscles" in response to temperature changes using shape memory polymers. Using the bistability instability, a small force can amplify the displacement to the maximum extent (Figure 5I).

\section{The Soft Actuators Mimicked via Parameter-Driven 4D Printing}

The $4 \mathrm{D}$ printing techniques relying on localized structure designs can only be implemented on a pixel-by-pixel basis that inherently limit its speed and resolution. In the process of 3D printing, the properties of printed parts are influenced by the processing parameters. For example, the parameters (e.g., extrusion rate and deposition speed, liquefying and cooling temperature, deposition path, and extrusion head diameter) affect the structures (e.g., degree of molecular order, crystallinity, strength of the line joint, and degree of anisotropy) and properties (e.g., modulus, glass transition temperature, anisotropy, and shape memory property) of the printed components (Bodaghi et al., 2017; Pilz Da Cunha et al., 2019; Zhang et al., 2019). The correlation between the parameters and the material structures (properties) offers us a practical method to regulate the shape-morphing behaviors of the printed components.

Yuk and Zhao (2018) reported a new strategy to print multiple diameters of fibers without changing the nozzle by simply selecting the appropriate printing parameters. Swelling actuator with a gradient $3 \mathrm{D}$ mesh has been printed by varying the moving speed and the printing height. As the actuator expands in the solvent, it initially bends to one direction and gradually flattens out (Figure 6A). However, they only build the quantitative phase diagrams for the new strategy, and the mechanism underneath is not clarified. In the following research, this concept is applied to smart materials, and the mechanisms have been gradually figured out. Changes in most parameters during the printing process always disturb the microstructures, which is eventually reflected in the deformations of these printed structures. Ren et al. (2020) demonstrated that by local modification of the print speed and print path in the $3 \mathrm{D}$ printing process, the orientating degrees of molecules of liquid crystal elastomers are dynamically coded. Hence, the shape-morphing and movement of the LCE strips can be fine sculpted (Figure 6B) (Ren et al., 2020). In addition to print speed, print height, and print path, print density has a direct effect on deformation as well. Nishiguchi et al. (2020) reported a biomimetic soft actuator with predetermined 3D geometry and programmed print density at pixel-by-pixel by tuning the writing distance in multiphoton lithography process. The smaller distance between the focal lines leads to a high printing density. The dynamic layer with low printing density is able to actuate in response to external stimuli, so the bilayer structure can exhibit anisotropic shape-morphing (Figure 6C). Sundaram et al. (2017) presented a manufacturing method of an electronic composite material that automatically folds at room temperature by locally engineered stress generated in the drop-on demand multimaterial 3Dprinting process. The stress is accumulated during the layer-bylayer 3D printing process. A portion of the new ink diffuses into the partially cross-linked layer below before UV light is applied. They automatically fold to form preprogrammed 3D structures upon release from their restraints (Figure 6D). When the liquid resin is cured by light radiation, the light conditions (light dose, light distribution, etc.) are the most important factors influencing the microstructures and the deformation. Huang et al. (2017) created self-deforming polymer networks with different crosslinking densities using different exposure times (light doses). The difference in cross-link density induces differential swelling of the sample in water, which turns the $2 \mathrm{D}$ film into a $3 \mathrm{D}$ object (Figure 6E). Subsequently, Kuang et al. (2019b) present broadly tailored functional gradients (light distribution) using grayscale light patterns to obtain functionally graded materials. The modulus of the customized gradient is up to three orders of magnitude and the glass transition temperature is up to $60^{\circ} \mathrm{C}$ (Figure 6F). Temperature also affects the microstructures of the active materials and, thus, influences the shape-morphing behaviors. Wang et al. (2020) reported a strategy to adjust the kinetic behavior and mechanical properties of printed filaments. Print temperature, nozzle size, and print height are dynamically regulated to investigate their influence on filament morphologies (Wang et al., 2020). As a proof of concept, they designed bilayer structures with six petals and with graded strain in the top layer by controlling the printing temperature, mimicking blooming flowers when heated in hot water (Figure 6G). Besides, Zhang et al. (2019) enabled 4D printing with monocomponent liquid crystal polymer inks with an orientation gradient perpendicular to the printing direction through the direct ink writing technology. Due to the temperature gradient between the two sides of the printed sample, an orientation gradient perpendicular to the printing direction is obtained, enabling a strip transforming to a tightly hollow cylinder. The liquidassisted printing or programmed structure design enables the integration of both bending and shrinking actuation modes on the same printed sample (Figure $\mathbf{6 H}$ ). In addition to the printing parameters of $3 \mathrm{D}$ printing itself, external assisting fields (magnetic, electric, etc.) also play an important role in controlling deformation. Tabrizi et al. (2019) exploited the combination of a reorientable magnetic field and spatially selective photopolymerization to independently define molecular orientation of liquid crystalline polymers in light- and/or heatresponsive multimaterial elements. They can adjust digital micromirrors and redirectable magnetic fields to construct complicated geometries like Gaussian curvatures, leading to the multiresponsive robotic manipulators (Figure 6I).

\section{The Soft Actuators Mimicked via Stimulus-Driven 4D Printing}

Most $4 \mathrm{D}$-printed soft actuators tend to focus on the design of the materials and structures of the actuators. These works are often accomplished prior to the 3D printing process. However, there is an alternative approach that allows for local anisotropic actuation as well-the selection and manipulation of multiple stimuli (Lee and Fang, 2012; Deng et al., 2018; Cui et al., 2019, 2020). Kotikian et al. (2019) printed untethered soft robotic matter that allows repeated shaping and self-propulsion in response to external stimuli. The liquid crystal elastomer bilayers are printed with the orthogonal director arrangement and different nematic to anisotropic transition temperatures. 


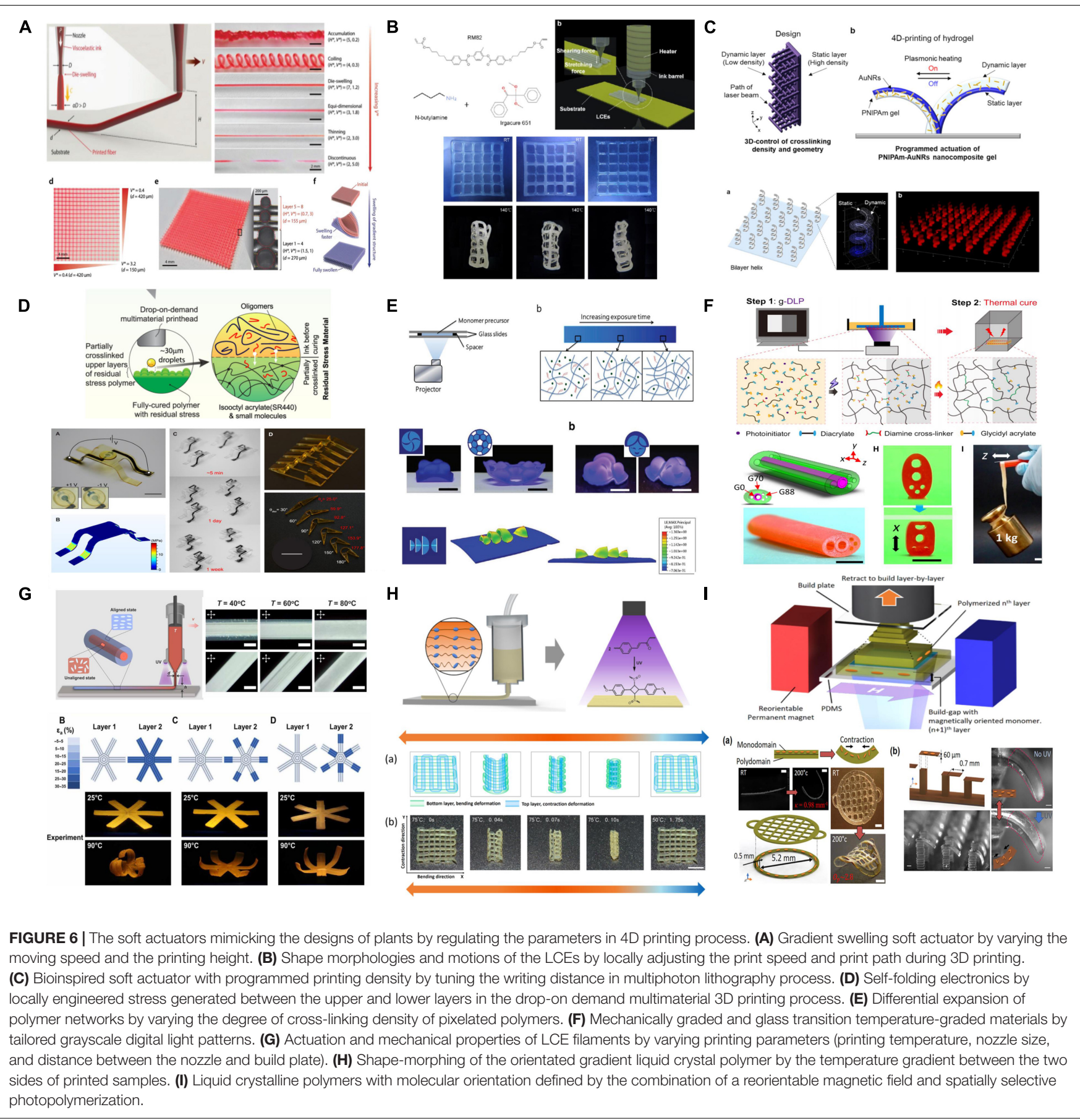

The soft robotic consists of active hinges that interconnect the polymer tiles. When heated above their respective actuation temperatures, the soft robotic exhibits three stable configurations and self-rolling in programmed reactions to thermal stimuli (Figure 7A). Light is also commonly used as sources of energy (light converting to heat) or stimuli (molecule transformation) in the soft actuation. del Pozo et al. (2020) presented lighttriggered bending actuators in response to temperature changes via liquid crystal oligomeric ink (Figure 7B). When illuminated at room temperature, the LCE actuator produces motion away from the light source. When lighting at high temperatures $\left(>45^{\circ} \mathrm{C}\right)$, the same actuator bends toward the direction of the light source. Besides, moisture in the atmosphere can also be manipulated to tune the dynamic performance in the $4 \mathrm{D}$ transformation. Correa et al. (2015) present a multimaterial printing method for designing components consisting of synthetic wood and polymers. The wood with moistureabsorbing and swelling properties achieves curling and selffolding behavior through 3D printing technology (Figure 7C). In addition to moisture changes, the chemical stimuli are also 


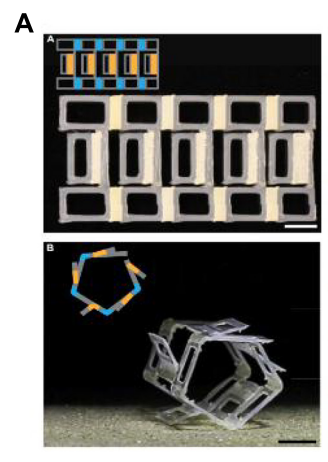

D
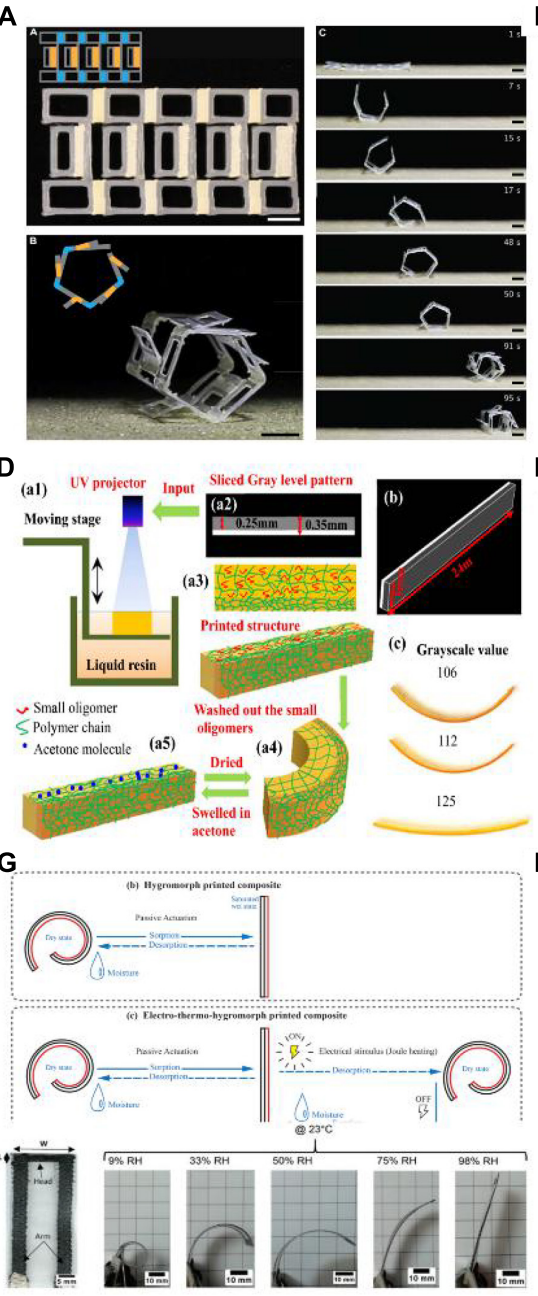

B

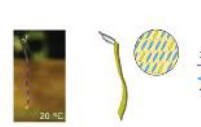
$\underset{455 \mathrm{~mm}}{\stackrel{355 \mathrm{~nm}}{\longrightarrow}}$ $\lfloor\downarrow \uparrow$
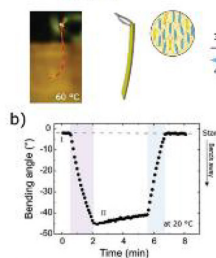

E a
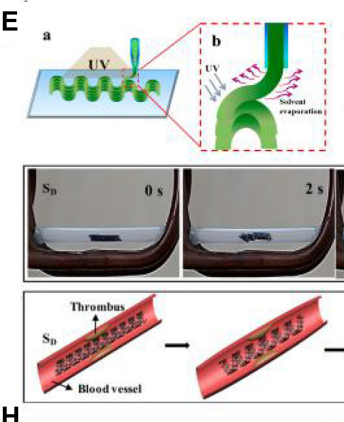

$\mathrm{H}$ 。

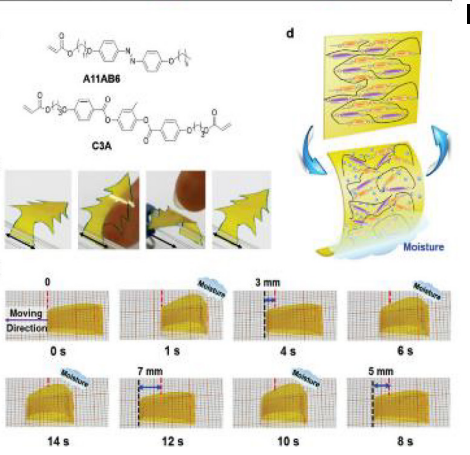

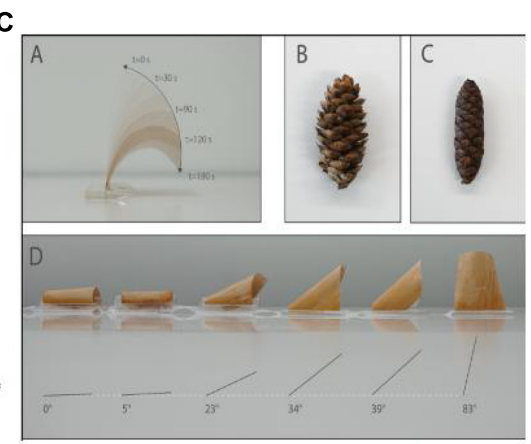
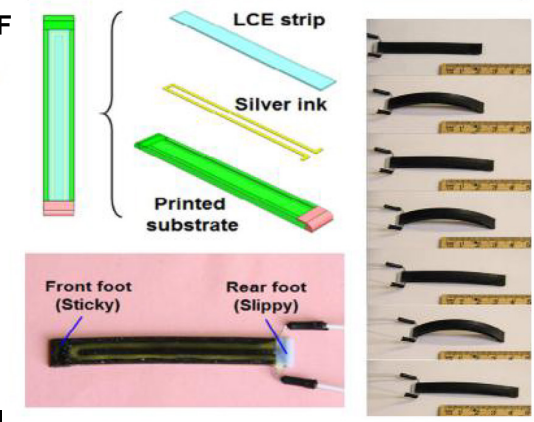

I
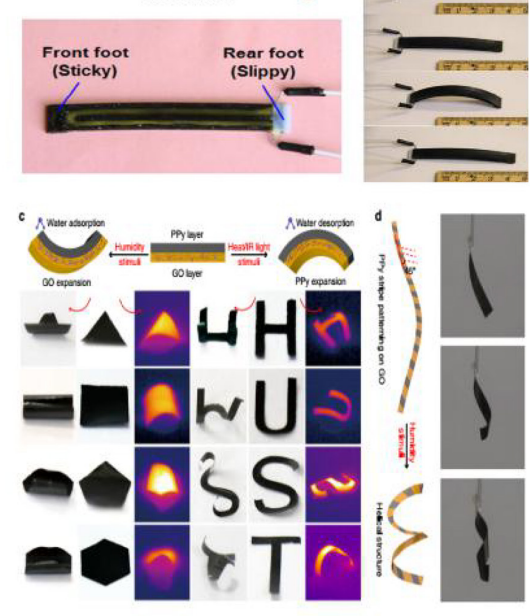

FIGURE 7 | The soft actuators mimicking the designs of plants by manipulating the stimulus in 4D printing process. (A) Shape-morphing and self-propelling of liquid crystal elastomer bilayers in programmed responses to thermal stimuli. (B) Amphibious light-fueled actuators generating motion toward/away from the light source regulated by temperature. (C) The curling and self-folding behaviors of wood in preprogrammed response to moisture. (D) Grayscale 4D-printed reversible self-folding structures by immersing in acetone and dried in air. (E) Active shape-changing architectures exhibiting magnetically guidable properties by the addition of iron oxide. (F) Joule heating stimulated active composites by printing conductive wires into LCE strips. (G) Multistimuli-responsive material by the addition of conductive carbon reinforcements into a moisture-sensitive polymer. $\mathbf{( H )}$ Hydrophobic cross-linked liquid crystal polymer film featuring both activation using moisture gradient and UV light. (I) Multiresponsive patternable actuator responding to humidity, temperature, and light via accurate structuring on graphene oxide films by the microstamping of hydrogel.

widely used for deformation. Wu et al. (2018) proposed that $3 \mathrm{D}$ grayscale printing could be employed to create reversible self-folding structures when immersed in acetone and dried in air. Removal of the uncured oligomer with acetone results in shrinkage of the polymer volume, inducing reversible selfexpansion/shrinkage deformation (Figure 7D). External fields (magnetic fields, electric fields, etc.) as a means of external stimulation often allow for more precise, localized actuation. Wei et al. (2017) integrated 4D shape-changing object by adding iron oxide to exhibit thermal and remotely actuated behavior (Figure 7E). Electricity is a frequently used energy for conventional actuators, and it is also applicable as local manipulation tools of soft actuators. Yuan et al. (2017) printed active composites by electronics and LCEs, where Joule heating produced by printed conductive wires is utilized to activate LCE strips. The strains generated between the LCE and the substrate cause the deflection of the hinge in the isotropic state (Figure 7F). The integration of several responsive moieties within one material and the combination of several materials with different stimuli response both endow smart materials with complex responsive behaviors. Le Duigou et al. (2019) proposed a multiresponsive composite material based on $4 \mathrm{D}$ printing with electrothermal dual actuation. Conductive carbon reinforcements and a moisture-sensitive polymer are used with a specific microstructure mimicking the anisotropic structure of pine cones. Changes in ambient humidity and electrical heating through the Joule effect can both actuate functional materials (Figure 7G). Liu et al. (2017) fabricated hydrophobic cross-linked 
liquid crystal polymer films with dual responses of humidity gradients and UV light. The film performs sophisticated motions by being exposed to humidity gradients. In addition, the film with the addition of azobenzene chromophores also responds to UV light. It tilts toward the incidence direction when irradiated by UV light ( $365 \mathrm{~nm}, 40 \mathrm{~mW} \mathrm{~cm}^{-2}$ ), and returns to the initial state when irradiated by light irradiation $\left(530 \mathrm{~nm}, 60 \mathrm{~mW} \mathrm{~cm}^{-2}\right.$ ) (Figure $7 \mathbf{H}$ ). Dong et al. (2019) proposed a multiresponsive actuator in response to humidity, temperature, and light by patterning on a graphene oxide film. They have developed a variety of biomimetic structures. Mimicking a hawk's claw and tendril, they designed intelligent grippers using crossed and spiral structures; mimicking the walk of an inchworm, they designed a soft walking robot that can move forward with the stimulation of infrared light (Figure 7I).

\section{CHALLENGES AND OUTLOOKS}

Plants are blueprints for us to understand how the tailored, hinge-free motions and motion sequences are generated via simple deformations in a microscale. Plant-inspired 4D printing presents a magnificent initiation into synthetic active materials and structures that can autonomously perceive and respond in a programmed way to the surroundings. How to design the program scheme and embed the programming logic into the materials is fundamental and crucial to $4 \mathrm{D}$ printing technology (Joshi et al., 2020). Plants provide the strategy for shape-morphing via compositional and structural design motifs. However, the correspondences between specific functions and functioning structures are not fully established. In the steps of biomimicry, it is essential to construct shape-shifting methodologies to have a better understanding of the actuation controllability. The given mechanisms should be able to be scaled, distorted, and reorganized to serve as a variety of structural motifs (Moulia, 2013).

In addition to the theoretical model, there is a need for practical software tools that can model and simulate the shape-shifting procedure. The software should be able to deal with the $4 \mathrm{D}$ behavior in a forward and/or inverse way, respectively. Currently, the vast majority of $4 \mathrm{D}$ printing researches are based on trial-and-error experiments, which need highly expert abilities and are often time-consuming. To facilitate the development and applications of 4D printing, accessible and straightforward software should be developed (Zolfagharian et al., 2020). In addition, to characterize biological materials with nonhomogeneous and ordered architecture, such as functionally graded materials, a special software is required. On the other

\section{REFERENCES}

Alapan, Y., Karacakol, A. C., Guzelhan, S. N., Isik, I., and Sitti, M. (2020). Reprogrammable shape morphing of magnetic soft machines. Sci. Adv. 6:eabc6414. doi: 10.1126/sciadv.abc6414

Armon, S., Efrati, E., Kupferman, R., and Sharon, E. (2011). Geometry and mechanics in the opening of chiral seed pods. Science 333, 1726-1730. hand, how to replicate the hierarchical and heterogeneous materials plant used via $4 \mathrm{D}$ printing process is another big challenge that plant-mimetic $4 \mathrm{D}$ printing faces. For most $3 \mathrm{D}$ printing technologies, they hardly have a control over the constituent and internal structure of the printed materials, which makes it difficult to fabricate such biomimetic materials. A whole workflow for $3 \mathrm{D}$ printing of bioinspired materials needs to be developed, involving slicer, firmware, and monitoring (Goh et al., 2020). A new slicer should enable a hybrid model to be processed, deriving not only geometrical but also material and structural information and even the process parameters as well (McPherson et al., 2020). Developments in new printing technologies that merge self-assembly with additive manufacturing to produce microstructural materials and process with the ability to print functionally graded materials are required (Loh et al., 2018).

In general, biomimetic $4 \mathrm{D}$ printing provides new design perspectives and fabrication tools for developing the next generation of functional structures that are adaptive in controlled or uncontrolled environmental cues. Its unique bottom-up manufacturing way makes it a promising candidate for the manufacturing of bioinspired hierarchical shape-morphing structures. Rather than just being a new concept, it is a manufacturing model. By the method of $4 \mathrm{D}$ printing, new products or applications with unique features that are difficult to manufacture in other ways will be available. Biomimetic 4D printing is still in the early and explosive boosting stage, and there will be a series of applications in a variety of fields in the near future. We envision that it will be extensively applicable to various fields ranging from soft robotics to medical, food, aerospace, and many other domains.

\section{AUTHOR CONTRIBUTIONS}

BL and QL wrote the manuscript. LQR and LR helped polish the language and rearranged the structure of the review. All authors contributed to the article and approved the submitted version.

\section{FUNDING}

The study was supported by the National Key Research and Development Program of China (Grant No. 2018YFF01012400).

\section{ACKNOWLEDGMENTS}

BL acknowledges the financial support of the China Scholarship Council (CSC).

Bodaghi, M., Damanpack, A. R., and Liao, W. H. (2017). Adaptive metamaterials by functionally graded 4D printing. Mater. Des. 135, 26-36. doi: 10.1016/j.matdes. 2017.08.069

Boley, J. W., van Rees, W. M., Lissandrello, C., Horenstein, M. N., Truby, R. L., Kotikian, A., et al. (2019). Shape-shifting structured lattices via multimaterial 4D printing. Proc. Natl. Acad. Sci. U.S.A. 116, 20856-20862. doi: 10.1073/pnas. 1908806116 
Braam, J. (2005). In touch: plant responses to mechanical stimuli. New Phytol. 165, 373-389. doi: 10.1111/j.1469-8137.2004.01263.x

Chen, T., Bilal, O. R., Shea, K., and Daraio, C. (2018). Harnessing bistability for directional propulsion of soft, untethered robots. Proc. Natl. Acad. Sci. U.S.A. 115, 5698-5702. doi: 10.1073/pnas.1800386115

Cho, K.-J., Koh, J.-S., Kim, S., Chu, W.-S., Hong, Y., and Ahn, S.-H. (2009). Review of manufacturing processes for soft biomimetic robots. Int. J. Precis. Eng. Manuf. 10, 171-181. doi: 10.1007/s12541-009-0064-6

Correa, D., Papadopoulou, A., Guberan, C., Jhaveri, N., Reichert, S., Menges, A., et al. (2015). 3D-printed wood: programming hygroscopic material transformations. 3D Print. Addit. Manuf. 2, 106-116. doi: 10.1089/3dp.2015. 0022

Correa, D., Poppinga, S., Mylo, M. D., Westermeier, A. S., Bruchmann, B., Menges, A., et al. (2020). 4D pine scale: biomimetic 4D printed autonomous scale and flap structures capable of multi-phase movement. Philos. Trans. R. Soc. A Math. Phys. Eng. Sci. 378:20190445. doi: 10.1098/rsta.2019.0445

Cui, H., Miao, S., Esworthy, T., Lee, S. Jr., Zhou, X., Hann, S. Y., et al. (2019). A novel near-infrared light responsive 4D printed nanoarchitecture with dynamically and remotely controllable transformation. Nano Res. 12, 13811388. doi: 10.1007/s12274-019-2340-9

Cui, H., Zhao, Q., Zhang, L., and Du, X. (2020). Intelligent polymer-based bioinspired actuators: from monofunction to multifunction. Adv. Intell. Syst. 2:2000138. doi: 10.1002/aisy.202000138

Dawson, C., Vincent, J. F. V., and Rocca, A.-M. (1997). How pine cones open. Nature 390, 668-668. doi: 10.1038/37745

De Marco, C., Pané, S., and Nelson, B. J. (2018). 4D printing and robotics. Sci. Robot. 3, 287-294. doi: 10.1126/scirobotics.aau0449

Deegan, R. D. (2012). Finessing the fracture energy barrier in ballistic seed dispersal. Proc. Natl. Acad. Sci. U.S.A. 109, 5166-5169. doi: 10.1073/pnas. 1119737109

del Pozo, M., Liu, L., Pilz da Cunha, M., Broer, D. J., and Schenning, A. P. H. J. (2020). Direct ink writing of a light-responsive underwater liquid crystal actuator with atypical temperature-dependent shape changes. Adv. Funct. Mater. 30:2005560. doi: 10.1002/adfm.202005560

Deng, H., Zhang, C., Su, J. W., Xie, Y., Zhang, C., and Lin, J. (2018). Bioinspired multi-responsive soft actuators controlled by laser tailored graphene structures. J. Mater. Chem. B. 6, 5415-5423. doi: 10.1039/c8tb01285g

Deshmukh, K., Houkan, M. T., AlMaadeed, M. A. A., and Sadasivunid, K. K. (2019). "Introduction to 3D and 4D printing technology: state of the art and recent trends," in $3 D$ and $4 D$ Printing of Polymer Nanocomposite Materials: Processes, Applications, and Challenges, eds K. Sadasivuni, K. Deshmukh, and M. A. AlMaadeed (Amsterdam: Elsevier), doi: 10.1016/B978-0-12-816805-9. 00001-6

Dong, Y., Wang, J., Guo, X., Yang, S., Ozen, M. O., Chen, P., et al. (2019). Multi-stimuli-responsive programmable biomimetic actuator. Nat. Commun. 10, 1-10. doi: 10.1038/s41467-019-12044-5

Du, S., and Yamamoto, F. (2007). An overview of the biology of reaction wood formation. J. Integr. Plant. Biol. 49, 131-143.

Dumais, J., and Forterre, Y. (2012). "Vegetable dynamicks": the role of water in plant movements. Annu. Rev. Fluid Mech. 44, 453-478. doi: 10.1146/annurevfluid-120710-101200

Durga Prasad Reddy, R., and Sharma, V. (2020). Additive manufacturing in drug delivery applications: a review. Int. J. Pharm. 589, 119820. doi: 10.1016/j. ijpharm.2020.119820

Egan, P., Sinko, R., LeDuc, P. R., and Keten, S. (2015). The role of mechanics in biological and bio-inspired systems. Nat. Commun. 6, 1-12. doi: 10.1038/ ncomms 8418

Elbaum, R., and Abraham, Y. (2014). Insights into the microstructures of hygroscopic movement in plant seed dispersal. Plant Sci. 223, 124-133. doi: 10.1016/j.plantsci.2014.03.014

Evangelista, D., Hotton, S., and Dumais, J. (2011). The mechanics of explosive dispersal and self-burial in the seeds of the filaree, Erodium cicutarium (Geraniaceae). J. Exp. Biol. 214, 521-529. doi: 10.1242/jeb.050567

Fagerstedt, K., and Karkonen, A. (2015). Plant cell wall. J. Integr. Plant Biol. 57, 326-445. doi: $10.1111 /$ jipb. 12351

Fan, W., Shan, C., Guo, H., Sang, J., Wang, R., Zheng, R., et al. (2019). Dualgradient enabled ultrafast biomimetic snapping of hydrogel materials. Sci. Adv. 5:eaav7174. doi: 10.1126/sciadv.aav7174
Forterre, Y. (2013). Slow, fast and furious: understanding the physics of plant movements. J. Exp. Bot. 64, 4745-4760. doi: 10.1093/jxb/ert230

Forterre, Y., Marmottant, P., Quilliet, C., and Noblin, X. (2016). Physics of rapid movements in plants. Europhys. News. 47, 27-30. doi: 10.1051/epn/2016104

Forterre, Y., Skotheim, J. M., Dumais, J., and Mahadevan, L. (2005). How the Venus flytrap snaps. Nature 433, 421-425. doi: 10.1038/nature03185

Ge, Q., Sakhaei, A. H., Lee, H., Dunn, C. K., Fang, N. X., and Dunn, M. L. (2016). Multimaterial 4D printing with tailorable shape memory polymers. Sci. Rep. 6 , 1-11. doi: $10.1038 /$ srep31110

Goh, G. D., Sing, S. L., and Yeong, W. Y. (2020). A review on machine learning in 3D printing: applications, potential, and challenges. Artif. Intell. Rev. 54, 63-94. doi: 10.1007/s10462-020-09876-9

Gregory, T. R. (2009). Understanding natural selection: essential concepts and common misconceptions. Evol. Educ. Outreach. 2, 156-175. doi: 10.1007/ s12052-009-0128-1

Guiducci, L., Razghandi, K., Bertinetti, L., Turcaud, S., Rüggeberg, M., Weaver, J. C., et al. (2016). Honeycomb actuators inspired by the unfolding of ice plant seed capsules. PLoS One 11:e0163506. doi: 10.1371/journal.pone.016 3506

Gul, J. Z., Sajid, M., Rehman, M. M., Siddiqui, G. U., Shah, I., Kim, K. H., et al. (2018). 3D printing for soft robotics-a review. Sci. Technol. Adv. Mater. 19, 243-262. doi: 10.1080/14686996.2018.1431862

Guo, Q., Dai, E., Han, X., Xie, S., Chao, E., and Chen, Z. (2015). Fast nastic motion of plants and bio-inspired structures. J. R. Soc. Interface. 12:20150598. doi: $10.1098 /$ rsif.2015.0598

Hashemi Farzaneh, H., Helms, M. K., Muenzberg, C., and Lindemann, U. (2016). "Technology-pull and biology-push approaches in bio-inspired design comparing results from empirical studies on student teams," in Proceedings of International Design Conference, eds M. Dorian, S. Mario, P. Neven, B. Nenad, and S. Stanko (Glasgow: DESIGN).

Hedrich, R., and Neher, E. (2018). Venus flytrap: how an excitable, carnivorous plant works. Trends Plant Sci. 23, 220-234. doi: 10.1016/j.tplants.2017. 12.004

Huang, L., Jiang, R., Wu, J., Song, J., Bai, H., Li, B., et al. (2017). Ultrafast digital printing toward $4 \mathrm{D}$ shape changing materials. Adv. Mater. 29:1605390. doi: 10.1002/adma.201605390

Jiang, Y., Korpas, L. M., and Raney, J. R. (2019). Bifurcation-based embodied logic and autonomous actuation. Nat. Commun. 10, 1-10. doi: 10.1038/s41467-01808055-3

Joshi, S., Rawat, K., Karunakaran, C., Rajamohan, V., Mathew, A. T., Koziol, K., et al. (2020). 4D printing of materials for the future: opportunities and challenges. Appl. Mater. Today 18:100490. doi: 10.1016/j.apmt.2019. 100490

Jung, W., Kim, W., and Kim, H.-Y. (2014). Self-burial mechanics of hygroscopically responsive awns. Integr. Comp. Biol. 54, 1034-1042. doi: 10.1093/icb/icu 026

Kanu, N. J., Gupta, E., Vates, U. K., and Singh, G. K. (2019). An insight into biomimetic 4D printing. RSC Adv. 9, 38209-38226. doi: 10.1039/c9ra07342f

Kim, H., Lee, H., Ha, I., Jung, J., Won, P., Cho, H., et al. (2018). Biomimetic color changing anisotropic soft actuators with integrated metal nanowire percolation network transparent heaters for soft robotics. Adv. Funct. Mater. 28:1801847. doi: $10.1002 /$ adfm.201801847

Kim, Y., Yuk, H., Zhao, R., Chester, S. A., and Zhao, X. (2018). Printing ferromagnetic domains for untethered fast-transforming soft materials. Nature 558, 274-279. doi: 10.1038/s41586-018-0185-0

Kotikian, A., McMahan, C., Davidson, E. C., Muhammad, J. M., Weeks, R. D., Daraio, C., et al. (2019). Untethered soft robotic matter with passive control of shape morphing and propulsion. Sci. Robot. 4:eaax7044. doi: 10.1126/ scirobotics.aax7044

Kotikian, A., Truby, R. L., Boley, J. W., White, T. J., and Lewis, J. A. (2018). 3D printing of liquid crystal elastomeric actuators with spatially programed nematic order. Adv. Mater. 30:1706164. doi: 10.1002/adma.201706164

Kuang, X., Roach, D. J., Wu, J., Hamel, C. M., Ding, Z., Wang, T., et al. (2019a). Advances in 4D printing: materials and applications. Adv. Funct. Mater. 29:1805290. doi: 10.1002/adfm.201805290

Kuang, X., Wu, J., Chen, K., Zhao, Z., Ding, Z., Hu, F., et al. (2019b). Grayscale digital light processing 3D printing for highly functionally graded materials. Sci. Adv. 5:eaav5790. doi: 10.1126/sciadv.aav5790 
Le Duigou, A., Chabaud, G., Scarpa, F., and Castro, M. (2019). Bioinspired electrothermo-hygro reversible shape-changing materials by $4 \mathrm{D}$ printing. Adv. Funct. Mater. 29:1903280. doi: 10.1002/adfm.201903280

Lee, H., and Fang, N. X. (2012). Micro 3D printing using a digital projector and its application in the study of soft materials mechanics. J. Vis. Exp. 69:e4457. doi: $10.3791 / 4457$

Liu, J., Erol, O., Pantula, A., Liu, W., Jiang, Z., Kobayashi, K., et al. (2019). Dual-Gel 4D printing of bioinspired tubes. ACS Appl. Mater. Interfaces 11, 8492-8498. doi: $10.1021 /$ acsami.8b17218

Liu, Y., Xu, B., Sun, S., Wei, J., Wu, L., and Yu, Y. (2017). Humidity- and photoinduced mechanical actuation of cross-linked liquid crystal polymers. $A d v$. Mater. 29:1604792. doi: 10.1002/adma.201604792

Loh, G. H., Pei, E., Harrison, D., and Monzón, M. D. (2018). An overview of functionally graded additive manufacturing. Addit. Manuf. 23, 34-44. doi: 10 . 1016/j.addma.2018.06.023

Lui, Y. S., Sow, W. T., Tan, L. P., Wu, Y., Lai, Y., and Li, H. (2019). 4D printing and stimuli-responsive materials in biomedical aspects. Acta Biomater. 92, 19-36. doi: 10.1016/j.actbio.2019.05.005

McCracken, J. M., Donovan, B. R., and White, T. J. (2020). Materials as machines. Adv. Mater. 32:1906564. doi: 10.1002/adma.201906564

McPherson, J., Bliss, A., Smith, F., Harriss, E., and Zhou, W. (2020). "A slicer and simulator for cooperative 3D printing. in Solid Freeform Fabrication 2017," in Proceedings of the 28th Annual International Solid Freeform Fabrication Symposium - An Additive Manufacturing Conference, SFF 2017, Fayetteville, AR.

Menges, A., Sheil, B., Glynn, R., Skavara, M., Correa, D., and Menges, A. (2017). "Fused filament fabrication for multi-kinematic-state climateresponsive aperture," in Fabricate, eds A. Menges, B. Sheil, R. Glynn, and M. Skavara (London: UCL Press), 44-47. doi: 10.2307/j.cttln7qkg7.30

Miriyev, A., Stack, K., and Lipson, H. (2017). Soft material for soft actuators. Nat. Commun. 8, 1-8. doi: 10.1038/s41467-017-00685-3

Mitchell, A., Lafont, U., Hołyńska, M., and Semprimoschnig, C. (2018). Additive manufacturing - A review of $4 \mathrm{D}$ printing and future applications. Addit. Manuf. 24, 606-626. doi: 10.1016/j.addma.2018.10.038

Momeni, F., Mehdi Hassani, N. S. M., Liu, X., and Ni, J. (2017). A review of 4D printing. Mater. Des. 122, 42-79. doi: 10.1016/j.matdes.2017.02.068

Montero de Espinosa, L., Meesorn, W., Moatsou, D., and Weder, C. (2017). Bioinspired polymer systems with stimuli-responsive mechanical properties. Chem. Rev. 117, 12851-12892. doi: 10.1021/acs.chemrev.7b00168

Moulia, B. (2013). Plant biomechanics and mechanobiology are convergent paths to flourishing interdisciplinary research. J. Exp. Bot. 64, 4617-4633. doi: 10. 1093/jxb/ert320

Nishiguchi, A., Zhang, H., Schweizerhof, S., Schulte, M. F., Mourran, A., and Möller, M. (2020). 4D printing of a light-driven soft actuator with programmed printing density. ACS Appl. Mater. Interfaces 12, 12176-12185. doi: 10.1021/ acsami.0c02781

Pfeifer, R., and Gomez, G. (2009). "Morphological computation - connecting brain, body, and environment," in Creating Brain-Like Intelligence. Lecture Notes in Computer Science, Vol. 5436, eds B. Sendhoff, E. Körner, O. Sporns, H. Ritter, and K. Doya (Berlin: Springer), 66-83. doi: 10.1007/978-3-642-00 616-6_5

Pfeifer, R., Lungarella, M., and Iida, F. (2012). The challenges ahead for bio-inspired "soft" robotics. Commun. ACM 55, 76-87. doi: 10.1145/2366316.2366335

Pilz Da Cunha, M., Peeketi, A. R., Mehta, K., Broer, D. J., Annabattula, R. K., Schenning, A. P. H. J., et al. (2019). A self-sustained soft actuator able to rock and roll. Chem. Commun. 55, 11029-11032. doi: 10.1039/c9cc05329h

Poppinga, S., Correa, D., Bruchmann, B., Menges, A., and Speck, T. (2020). Plant movements as concept generators for the development of biomimetic compliant mechanisms. Integr. Comp. Biol. 60, 886-895. doi: 10.1093/icb/icaa028

Poppinga, S., Hartmeyer, S. R. H., Seidel, R., Masselter, T., Hartmeyer, I., and Speck, T. (2012). Catapulting tentacles in a sticky carnivorous plant. PLoS One. 7:e45735. doi: 10.1371/journal.pone.0045735

Poppinga, S., Haushahn, T., Warnke, M., Masselter, T., and Speck, T. (2015). Sporangium exposure and spore release in the peruvian maidenhair fern (Adiantum peruvianum, Pteridaceae). PLoS One. 10:e0138495. doi: 10.1371/ journal.pone.0138495

Poppinga, S., Weisskopf, C., Westermeier, A. S., Masselter, T., and Speck, T. (2016). Fastest predators in the plant kingdom: functional morphology and biomechanics of suction traps found in the largest genus of carnivorous plants. AoB Plants 8:lv140. doi: 10.1093/aobpla/plv140

Quan, H., Kisailus, D., and Meyers, M. A. (2020). Hydration-induced reversible deformation of biological materials. Nat. Rev. Mater. 6, 264-283. doi: 10.1038/ s41578-020-00251-2

Ren, L., Li, B., He, Y., Song, Z., Zhou, X., Liu, Q., et al. (2020). Programming shape-morphing behavior of liquid crystal elastomers via parameter-encoded 4D printing. ACS Appl. Mater. Interfaces 12, 15562-15572. doi: 10.1021/acsami. 0c00027

Reyssat, E., and Mahadevan, L. (2009). Hygromorphs: from pine cones to biomimetic bilayers. J. R. Soc. Interface 6, 951-957. doi: 10.1098/rsif.2009.0184

Sakes, A., van der Wiel, M., Henselmans, P. W. J., van Leeuwen, J. L., Dodou, D., and Breedveld, P. (2016). Shooting mechanisms in nature: a systematic review. PLoS One 11:e0158277. doi: 10.1371/journal.pone.0158277

Scorza, L. C. T., and Dornelas, M. C. (2011). Plants on the move: toward common mechanisms governing mechanically-induced plant movements. Plant Signal. Behav. 6, 1979-1986. doi: 10.4161/psb.6.12.18192

Selaginella, R. P., Western, T. L., Pasini, D., and Rafsanjani, A. (2015). Hydroresponsive curling of the resurrection plant Selaginella lepidophylla. Sci. Rep. 5:8064. doi: $10.1038 /$ srep08064

Shafranek, R. T., Millik, S. C., Smith, P. T., Lee, C. U., Boydston, A. J., and Nelson, A. (2019). Stimuli-responsive materials in additive manufacturing. Prog. Polym. Sci. 93, 36-67. doi: 10.1016/j.progpolymsci.2019.03.002

Skotheim, J. M. (2005). Physical limits and design principles for plant and fungal movements. Science 308, 1308-1310. doi: 10.1126/science.1107976

Song, Z., Ren, L., Zhao, C., Liu, H., Yu, Z., Liu, Q., et al. (2020). Biomimetic nonuniform, dual-stimuli self-morphing enabled by gradient four-dimensional printing. ACS Appl. Mater. Interfaces 12, 6351-6361. doi: 10.1021/acsami. $9 \mathrm{~b} 17577$

Studart, A. R., and Erb, R. M. (2014). Bioinspired materials that self-shape through programmed microstructures. Soft Matter 10, 1284-1294. doi: 10.1039/ C3SM51883C

Sun, L., Li, J., Chen, Y., Yang, Y., Tao, Y., Wang, G., et al. (2020). “4DTexture: a shape-changing fabrication method for 3D surfaces with texture," in Proceedings of the Conference on Human Factors in Computing Systems, (New York, NY: Association for Computing Machinery), 1-7. doi: 10.1145/3334480.3383053

Sundaram, S., Kim, D. S., Baldo, M. A., Hayward, R. C., and Matusik, W. (2017). 3D-printed self-folding electronics. ACS Appl. Mater. Interfaces 9, 32290-32298. doi: $10.1021 /$ acsami.7b10443

Sydney Gladman, A., Matsumoto, E. A., Nuzzo, R. G., Mahadevan, L., and Lewis, J. A. (2016). Biomimetic 4D printing. Nat. Mater. 15, 413-418. doi: 10.1038/ nmat 4544

Tabrizi, M., Ware, T. H., and Shankar, M. R. (2019). Voxelated molecular patterning in three-dimensional freeforms. ACS Appl. Mater. Interfaces 11, 28236-28245. doi: 10.1021/acsami.9b04480

Tseng, T. L. B., Akundi, A., and Kim, H. (2018). "4-D printing of pressure sensors and energy harvesting devices for engineering education," in ASEE Annual Conference and Exposition, Conference Proceedings, (Washington, DC: ASEE), doi: 10.18260/1-2-29654

Vincent, J. F. V., Bogatyreva, O. A., Bogatyrev, N. R., Bowyer, A., and Pahl, A.K. (2006). Biomimetics: its practice and theory. J. R. Soc. Interface 3, 471-482. doi: 10.1098/rsif.2006.0127

Volkov, A. G., Foster, J. C., Ashby, T. A., Walker, R. K., Johnson, J. A., and Markin, V. S. (2010a). Mimosa pudica: Electrical and mechanical stimulation of plant movements. Plant Cell Environ. 33, 163-173. doi: 10.1111/j.1365-3040.2009. 02066.x

Volkov, A. G., Foster, J. C., Baker, K. D., and Markin, V. S. (2010b). Mechanical and electrical anisotropy in Mimosa pudica pulvini. Plant Signal. Behav. 5, 1211-1221. doi: 10.4161/psb.5.10.12658

Wang, G., Do, Y., Cheng, T., Yang, H., Tao, Y., Gu, J., et al. (2018). "Demonstrating printed paper actuator: a low-cost reversible actuation and sensing method for shape changing interfaces," in Conference on Human Factors in Computing Systems - Proceedings, Yokohama, doi: 10.1145/3170427.318 6531

Wang, G., Tao, Y., Capunaman, O. B., Yang, H., and Yao, L. (2019). "A-line: $4 \mathrm{D}$ printing morphing linear composite structures," in Conference on Human Factors in Computing Systems - Proceedings, (New York, NY: Association for Computing Machinery), doi: 10.1145/3290605.3300656 
Wang, W., Li, C., Cho, M., and Ahn, S. H. (2018). Soft tendril-inspired grippers: shape morphing of programmable polymer-paper bilayer composites. ACS Appl. Mater. Interfaces 10, 10419-10427. doi: 10.1021/acsami.7b1 8079

Wang, Z., Wang, Z., Zheng, Y., He, Q., Wang, Y., and Cai, S. (2020). Threedimensional printing of functionally graded liquid crystal elastomer. Sci. $A d v$. 6:eabc0034. doi: 10.1126/sciadv.abc0034

Wei, H., Zhang, Q., Yao, Y., Liu, L., Liu, Y., and Leng, J. (2017). Direct-write fabrication of $4 \mathrm{D}$ active shape-changing structures based on a shape memory polymer and its nanocomposite. ACS Appl. Mater. Interfaces 9, 876-883. doi: 10.1021/acsami.6b12824

Wu, J., Zhao, Z., Kuang, X., Hamel, C. M., Fang, D., and Qi, H. J. (2018). Reversible shape change structures by grayscale pattern $4 \mathrm{D}$ printing. Multifunct. Mater. 1:015002.

Yang, C., Boorugu, M., Dopp, A., Ren, J., Martin, R., Han, D., et al. (2019). 4D printing reconfigurable, deployable and mechanically tunable metamaterials. Mater. Horizons 6, 1244-1250. doi: 10.1039/c9mh00302a

Yang, N. J., and Hinner, M. J. (2015). Getting across the cell membrane: an overview for small molecules, peptides, and proteins. Methods Mol. Biol. 1266, 29-53. doi: 10.1007/978-1-4939-2272-7_3

Yang, R., Zhou, J., Yang, C., Qiu, L., and Cheng, H. (2020). Recent progress in 3D printing of 2D material-based macrostructures. Adv. Mater. Technol. 5:1901066. doi: 10.1002/admt.201901066

Yin, J., Cao, Z., Li, C., Sheinman, I., and Chen, X. (2008). Stress-driven buckling patterns in spheroidal core/shell structures. Proc. Natl. Acad. Sci. U.S.A. 105, 19132-19135. doi: 10.1073/pnas.0810443105

Yuan, C., Roach, D. J., Dunn, C. K., Mu, Q., Kuang, X., Yakacki, C. M., et al. (2017). 3D printed reversible shape changing soft actuators assisted by liquid crystal elastomers. Soft Matter 13, 5558-5568. doi: 10.1039/c7sm0 0759k

Yuk, H., and Zhao, X. (2018). A new 3D printing strategy by harnessing deformation, instability, and fracture of viscoelastic inks. Adv. Mater 30:1704028. doi: 10.1002/adma.201704028
Zambrano, D., Cianchetti, M., and Laschi, C. (2014). "The morphological computation principles as a new paradigm for robotic design," in Opinions and Outlooks on Morphological Computation, eds H. Hauser, R. Fuchslin, and R. Pfeifer (Zurich: E-Book), 214-225. doi: 10.13140/2.1.1059. 4242

Zhang, C., Lu, X., Fei, G., Wang, Z., Xia, H., and Zhao, Y. (2019). 4D printing of a liquid crystal elastomer with a controllable orientation gradient. ACS Appl. Mater. Interfaces 11, 44774-44782. doi: 10.1021/acsami.9b18037

Zhang, Y., Huang, L., Song, H., Ni, C., Wu, J., Zhao, Q., et al. (2019). 4D printing of a digital shape memory polymer with tunable high performance. ACS Appl. Mater. Interfaces 11, 32408-32413. doi: 10.1021/acsami.9b1 1062

Zhang, Z., Demir, K. G., and Gu, G. X. (2019). Developments in 4Dprinting: a review on current smart materials, technologies, and applications. Int. J. Smart Nano Mater. 10, 205-224. doi: 10.1080/19475411.2019.159 1541

Zolfagharian, A., Kaynak, A., and Kouzani, A. (2020). Closed-loop 4Dprinted soft robots. Mater. Des. 188:108411. doi: 10.1016/j.matdes.2019. 108411

Conflict of Interest: The authors declare that the research was conducted in the absence of any commercial or financial relationships that could be construed as a potential conflict of interest.

The reviewer YL declared a shared affiliation with several of the authors, LQR, BL, $\mathrm{KW}, \mathrm{XZ}, \mathrm{ZS}$, and QL, to the handling editor at time of review.

Copyright (c) 2021 Ren, Li, Wang, Zhou, Song, Ren and Liu. This is an open-access article distributed under the terms of the Creative Commons Attribution License (CC BY). The use, distribution or reproduction in other forums is permitted, provided the original author(s) and the copyright owner(s) are credited and that the original publication in this journal is cited, in accordance with accepted academic practice. No use, distribution or reproduction is permitted which does not comply with these terms. 